\title{
COMMUNAL ORIENTATION PREDICTING MARITAL FLOURISHING: ANALYZING MODERATED-MEDIATION MODEL OF EXPRESSION AND REGULATION OF EMOTIONS AMONG MARRIED SAMPLE
}

\author{
Samar Fahd (Corresponding Author) \\ Assistant Professor, Department of Applied Psychology, The Islamia University of Bahawalpur. Email: samar.fahd@iub.edu.pk \\ Rubina Hanif \\ Associate Professor, National Institute of Psychology. Quid-e-Azam University, Islamabad. Email: drrubinahanif@nip.edu.pk \\ Fatima Khurram Bukhari \\ Assistant Professor, Department of Applied Psychology, The Islamia University of Bahawalpur. \\ Email: fatima.khurram@iub.edu.pk \\ Muzammila Akram \\ Assistant Professor, Department of Educational Training, The Islamia University of Bahawalpur. \\ Email: muzammila.akram@iub.edu.pk \\ Asia Kausar, Lecturer, Department of Applied Psychology, The Islamia University of Bahawalpur. \\ Email: asia.kausar@iub.edu.pk \\ Qurat-ul-ain Shams \\ M.Phil Scholar, Department of Educational Training, The Islamia University of Bahawalpur. Email: quratulain272@gmail.com \\ Safia Rashid \\ Assistant Professor, Department of Psychology, Women University, Multan. Email: safia.rashidch@yahoo.com \\ Nabila Maqbool \\ M.Phil Psychology, Department of Applied Psychology, The Islamia University of Bahawalpur. \\ Email: nabilazahid038@gmail.com \\ Raheen Tariq \\ B.S. Scholar, Department of Applied Psychology, The Islamia University of Bahawalpur. Email: reen.tariq1@ outlook.com \\ Syeda Sidra Nosheen \\ Lecturer, Department of Educational Training, The Islamia University of Bahawalpur. Email: sidra.nosheen@ymail.com
}

\section{ABSTRACT:}

The current research explores the role of communal orientation, emotional expressivity and emotional regulation to determine marital flourishing of married population. Data is collected from married individuals belonging to diverse social, economic and professional backgrounds using standardized selfreport questionnaires. The study uses survey research design. SPSS 21 version analyses the data using correlations, regression and moderated-mediated models. Results indicate that communal orientation is significant predictor of marital flourishing. Findings also reveal that moderation of emotion expressivity and mediation of emotion regulation buffers connection between communal orientation and marital flourishing amongst married population. The current research carries implications for relationship counselors, family researchers and positive psychologists.

KEYWORD: Communal Orientation, Emotional Expressivity, Emotional Regulation, Flourishing, Marriage 


\section{INTRODUCTION}

Relationships are one of the most effective ways to begin flourishing and to advance towards positivity in life. Relationship researchers have been successful in uncovering the factors that could make their relationships flourishing. Notion of flourishing in marriages indicates that contented marriage is reflected in the lives of the partners. A flourishing marriage is not merely depicted by the subjective happiness or contentment of husband and wife. The partners consistently connect to each other and act in ways that aimed to acquire common goals in marriage. Moreover, a flourishing marital relationship does not merely aim to satisfy spouses, but also enabling each other to grow, prosper and flourish. Hence, the idea of flourishing is an action-based process of practicing the ways that develop momentum for a flourishing marital relationship (Fowerz \& Owenz, 2010).

\section{LITERATURE REVIEW}

Literature highlight evidences on flourishing relationships as relationships that continue to get better due to concerted effort of both partners. Current body of research depicts studies documenting the role of factors that enhance flourishing of married relationship, including thankfulness (Gordon, Arnette \&
Smith, 2011), benefit from positive events (Emmons \& McCullough, 2003; Watkins et al., 2003), social support (Barry, Bunde, Brock \& Lawrence, 2009), emotional responsiveness for the spouse (Driver \& Gottman, 2004), appreciation and positive response (Mirgain \& Cordova, 2007), sexual intimacy and communication manners (Yoo, Bartle-Haring, Day \& Gangamma, 2014), sacrifice (Stanley, Whitton, Sadberry, Clements \& Markman, 2006), humor (Ziv \& Gadish, 1989) forgiveness (Orathinkal \& Vansteenwegen, 2006) high self-esteem (Oprisan \& Cristea, 2012). Numerous other factors that could enhance marital flourishing of married population include, financial stability, education, reverence for partner's individual differences \& expectations from the spouse (Fahd \& Hanif, 2018).

\section{Communal Orientation as Predictor of} Marital Flourishing

Construct of communal orientation (CO) manifests enhanced magnitude of enthusiasm to react towards partner's need (Mills \& Clark, 2001). Communally orientated people are emotionally responsive whenever their partners' need them and they are also fond of helping others. Individuals high in communal orientation are expected 
to experience better psychological functioning. Such individuals enjoy a number of interpersonal and intrapersonal qualities like high self-esteem, personal satisfaction, and strong bonds of empathy (Le, Impett, Kogan, Webster, \& Cheng, 2013). Moreover, those individuals are determined to behave communally toward their spouse and are intrinsically motivated to make sacrifices in their interpersonal relationships (Kogan et al., 2010).

However, though existing studies has recognized the benefits of giving communal care, investigation has yet to explore the rewards of possessing a communal orientation within marital relationship. Thus, dwelling upon the existing literature in terms of the interpersonal benefits of communal care for the partner, our investigation focuses on the level of communal orientation illustrated by husbands and wives and the amount of marital flourishing predicted by communal orientation. Moreover, besides the prediction of communal orientation in predicting psychological flourishing of married population, mediation of emotional expression might also demonstrate to be critical for describing a flourishing marital relationship (Clark \& Finkel, 2005).
Emotion Expressivity: Moderating between Communal Orientations and Flourishing

Existing research recommends that emotional expressiveness (EE) plays vital part within interpersonal relationships (Geist \& Gilbert, 1996; Gottman \& Levenson, 1992). Psychologists have proved that husband and wife's emotional expressivity is highly associated to their marital satisfaction (Wang, Wang, Feeney, \& Li, 2017). The expression of emotions such as affection and warmth serve to engender a sense of closeness and trust in the relationship. On the contrary, the display of emotions such as anger, unpleasantness, or annoyance may lead to the perception of the relationship as disturbed and unproductive (Gill, Christensen, \& Fincham, 1999; Folkman \& Moskowitz, 2000).

Numerous researches also suggest that expressing emotions may increase the mindfulness in terms of one's own emotional condition as well as that of one's spouse, thus, forming an intimate and satisfying relationship (Carrere \& Gottman, 1999). However, several evidences also exist that shows no link between emotional expression and happiness of married relationship (e.g Yediri \& Hamarta, 2015). While it is fairly well established that 
emotional expressivity is related with marital happiness, it is still unclear that either, it serves as buffering variable that moderate the relationship between communal orientation and flourishing, or not.

Therefore, expression of emotions is needed to be studied as it moderates the path between cooperative and helping behaviors (communal orientation) and flourishing among married population. Along with the expressive function, regulation of emotions might also mediate the relationship between communal orientation and flourishing of married population. Hence, the present research also examines the role of emotional regulation (ER) mediating between communal orientation and marital flourishing.

\section{Emotion Regulation: Mediating between} Communal Orientations and Flourishing

Emotion regulation (ER) is considered to be a significant component for flourishing of interpersonal relationships. Marriage is crucible for regulation of emotional responses (Levenson et al., 2013). Effective emotional regulation might reduce negative emotional arousal that is favorable for effective communication and conflict resolution (Levenson et al, 2013). Gross (2001) points out two principal strategies of emotional regulation: Cognitive Reappraisal (CR) \& Expressive Suppression (ES). CR is conceptualized as the effort to interpret an emotion-prompting state in the manner that modifies its meaning and alters its emotional effect (Gross \& John, 2003); whereas, ES is described as the attempt to conceal, constrain or reduce ongoing emotionexpressive behavior (Gross and Levenson, 1992; Gross and John, 2003).

Numerous researches in literature indicate that $\mathrm{CR}$ and $\mathrm{ES}$ is associated to several psychological outcomes. CR is positively correlated with psychological health, including improved satisfaction in life (Haga, Kraft, \& Corby, 2009), positive affect (Cabello, Salguero, FernándezBerrocal, \& Gross, 2013), high self-esteem, and better social bonds (John \& Gross, 2004) and reduced symptoms of stress. Whereas, ES is connected with higher negative effects in terms of emotional and social values (John \& Gross, 2004). However, despite literature's evidences elucidating the role of emotion regulation strategies in interpersonal functioning, very few studies report the exploration of ER strategies in terms of relationship flourishing among married sample. 
PURPOSE OF PRESENT RESERCH

The present study addresses the substantial literature deficit regarding role of emotion expressivity (moderator) and emotion regulation (mediator) combining to influence the impact of communal orientations predicting marital flourishing. Moreover, in order to promote flourishing in long-term marriages, a comprehensive framework of theoretically significant variables like emotions and communal tendencies is deemed necessary. The current research is distinctively designed to document the importance of emotional and communal processes within marital context and simultaneously targeting multiple components such as positive and negative emotional expressivity, emotion regulation strategies, positive and negative communal tendencies as determinant of marital flourishing among non-western married sample.

\section{OBJECTIVES}

- To analyze relationship patterns among flourishing, communal orientation, emotion expressivity and emotional regulation (Bivariate Correlation).

- To analyze role of communal orientation predicting psychological flourishing among married sample (Linear Regression Analysis)

- To analyze moderated mediating model of emotion expressivity and emotion regulation between the association of communal orientation and flourishing of married population (MACRO PROCESSModel 59).

\section{HYPOTHESES}

- Communal Orientation positive subscale would positively predict Marital Flourishing among wives and husbands.

- Communal Orientation negative subscale would negatively predict Marital Flourishing among wives and husbands.

- Emotional Expressivity and Emotional Regulation would yield significant interaction as moderatedmediated role between the association of Communal Orientation and Flourishing among married population.

\section{RESEARCH INSTRUMENTS}

Data of the research was collected using the following research instruments. 
1. Demographic Profile Sheet: Husbands and wives were required to give information about the following: their age, education, years of professional experience, number of marital years, family system, children, and type of marriage.

2. Communal Orientation Scale (Predicting Variable): Communal Orientation of married individuals was assessed through Communal Orientation Scale- Urdu (COS-U; Clark et al., 1987). Fourteen items of this scale assesses disposition to be caring for the partner. Two subscales of COS-U were framed named as communal orientation positive (COP) and communal orientation negative $(\mathrm{CON})$. Scoring of communal questionnaire was done on continuous basis.

3. Psychological Flourishing Scale (Outcome Variable). Psychological flourishing Scale (PFS; Fahd \& Hanif, 2017) consists of two subscales that measures psychological flourishing of husbands and wives in terms of two dimensions; relationship dimension (21 items) and individual dimension (18 items). Relationship dimension of PFS includes questions about understanding, friendly relations, appreciation, capitalizing on positive events etc. whereas, the individual dimension includes items about one's personal qualities like sense of humor, level of self-esteem, emotional stability, optimism etc. Each item of the scale is scored on five-point scale. All the responses are added to get a total score.

4. Berkeley Expressivity QuestionnaireUrdu (Moderating Variable). Berkeley Emotion Expressivity Questionnaire (BEQ-U; Gross \& John, 1995) was administered to assess positive and negative emotion expressivity. Items from the scale include: "I sometimes cry during sad movies;" "I've learned it is better to suppress my anger than to show it"; "My body reacts very strongly to emotional situations." Each item of the scale is scored on 5-point scale.

5. Emotion Regulation QuestionnaireUrdu (Mediating Variable) The Emotion Regulation Questionnaire (ERQ-U; Khan \& Kausar, 2014) is a 10 item scale focusing the processes of emotion regulation and management. The questionnaire 
consists of two subscales; cognitive reappraisal and expressive suppression on a 5- point Likert scale. Scale included items like: "When I'm faced with a stressful

\section{METHOD}

A national sample of married individuals' $43.2 \%$ husbands and $56.8 \%$ wives participated in this scientific study (Table 1). Respondents' were contacted for the completion of research questionnaire and socio-demographic information form. Study situation, I make myself think about it in a way that helps me stay calm"; "When I want to feel more positive emotion, I change the way I'm thinking about the situation". objectives and rationale were briefed to the participants. Every respondent was granted two days to complete the questionnaire. All the participants were thanked for sparing their time and sharing their personal information for the purpose of research. 


\section{Table 1}

Demographic Characteristics of the sample for Moderated-Mediation Analysis.

\begin{tabular}{|c|c|c|c|c|c|c|}
\hline \multirow[b]{2}{*}{ Characteristics } & \multicolumn{3}{|c|}{ Wives } & \multicolumn{3}{|c|}{ Husbands } \\
\hline & Mean & $S D$ & Frequency (\%) & Mean & $S D$ & Frequency $(\%)$ \\
\hline Age(in yrs) & 35.52 & 9.58 & & 40.88 & 10.73 & \\
\hline $20-30$ & & & $226(39.7)$ & & & 72(16.66) \\
\hline $31-40$ & & & $209(36.7)$ & & & $174(40.2)$ \\
\hline $41-50$ & & & $98(17.2)$ & & & $111(25.6)$ \\
\hline $51-60$ & & & $26(4.6)$ & & & 55() 12.7 \\
\hline $61-70$ & & & $10(1.8)$ & & & $14(3.2)$ \\
\hline $71-80$ & & & $6(0.6)$ & & & $6(1.4)$ \\
\hline Education & 3.27 & 1.27 & & 3.14 & 1.32 & \\
\hline Matric & & & $86(15.1)$ & & & $80(18.5)$ \\
\hline Intermdite & & & $60(10.5)$ & & & $51(11.8)$ \\
\hline Bachelor & & & $105(18.5)$ & & & $72(16.6)$ \\
\hline Masters & & & $250(43.9)$ & & & $187(43.2)$ \\
\hline M.Phill & & & $52(9.1)$ & & & $29(6.1)$ \\
\hline Ph.D & & & $10(1.8)$ & & & $9(2.1)$ \\
\hline Profession & 1.98 & 1.06 & & 3.41 & 0.77 & \\
\hline Housewife & & & $215(37.8)$ & & & \\
\hline Teacher & & & $213(37.4)$ & & & $77(17.8)$ \\
\hline Business & & & $17(3.0)$ & & & $97(22.4)$ \\
\hline Job & & & $93(16.3)$ & & & $250(57.7)$ \\
\hline FamilySys & 1.49 & 0.55 & & 1.53 & 0.5 & \\
\hline Neclear & & & 271(47.6) & & & $186(43.0)$ \\
\hline Joint & & & $247(43.4)$ & & & $210(48.5)$ \\
\hline YofMarri & 12.28 & 9.57 & & 14.08 & 10.5 & \\
\hline 1 to 10 & & & $309(54.3)$ & & & $207(47.8)$ \\
\hline 11 to 20 & & & $150(26.4)$ & & & $115(26.6)$ \\
\hline 21 to 30 & & & $80(14.1)$ & & & $76(17.6)$ \\
\hline 31 to 40 & & & $20(3.5)$ & & & $27(6.2)$ \\
\hline 41 to 50 & & & $6(1.1)$ & & & $5(1.2)$ \\
\hline TyofMarri & 1.34 & 0.65 & & 1.39 & 0.64 & \\
\hline Love & & & $423(79.4)$ & & & $289(66.7)$ \\
\hline Arrange & & & $88(15.5)$ & & & $98(22.6)$ \\
\hline
\end{tabular}


Relationship of Study Variables: Bivariate correlation was computed to explore relationship among study variables. Numerical figures depict that there is significant association among all study variables (Table 2). Predictor (CO) is significantly correlated with outcome (Psychological Flourishing). While, moderator (Emotion Expressivity) is negatively correlated with marital flourishing of married individuals. Likewise, mediator (ER) is also negatively correlated with marital flourishing. Data of the present investigation supports the findings in terms of positive relationship between communal orientation and marital flourishing by illustrating that the sensitivity to the problems of others and to facilitate them in as reaction to their needs tends to be significant variable of satisfaction in interpersonal relationships.

Similarly, negative link between emotion expressivity and flourishing within present data of non-western married population contradicts the existing empirical literature on emotions that depicts that spouses' nature of emotional expressivity is greatly linked to their marital satisfaction (Gill, Christensen, \& Fincham, 1999). Moreover, emotion regulation is negatively correlated with marital flourishing. Cross-cultural evidences have provided support for the notion that in communalist cultures, there is preference for suppression of emotional responses, cognitive reappraisal strategy is more functional in western cultures as compared to the eastern cultures (De Leersnyder, Boiger, \& Mesquita, 2013). Moreover, in different studies, participants from independent cultural contexts have shown to express preference for reappraisal rather than suppression than the respondents from interdependent culture. The differences, undoubtly, correspond to cultural norms (Butler, 2015; Mauss \& Gross, 2004). 
Table 2

Correlation Coefficient among all the Variables of the Study $(N=1002)$.

\begin{tabular}{|c|c|c|c|c|c|c|c|c|c|c|}
\hline Variables & 1 & 2 & 3 & 4 & 5 & 6 & 7 & 8 & 9 & 10 \\
\hline $\mathrm{CO}$ & & $-.13^{*}$ & $-.21 * *$ & $-.26 * *$ & -.00 & $.10 * *$ & $-.25 * *$ & $.12 *$ & $.17 * *$ & $.17 * *$ \\
\hline $\mathrm{NE}$ & & & $.40 * *$ & $.42 * *$ & $-.11 *$ & $-.36 * *$ & $76^{* *}$ & .06 & -.10 & -.02 \\
\hline PE & & & & $.55^{* *}$ & $.16^{* *}$ & $-.16^{* * *}$ & $.76^{* *}$ & -.04 & $-.29 * *$ & $-.19 * *$ \\
\hline $\mathrm{ER}(\mathrm{R})$ & & & & & & $.58 * *$ & .10 & -.10 & $-.17 * *$ & $-.15^{* *}$ \\
\hline $\mathrm{ER}(\mathrm{S})$ & & & & & & & $-.20 * *$ & $-.14 * *$ & -.04 & -.10 \\
\hline EE(Total) & & & & & & & & -.07 & $-.27 * *$ & $-.19 * *$ \\
\hline F (Rel) & & & & & & & & & $.53 * *$ & $.87 * *$ \\
\hline F (Ind) & & & & & & & & & & $.86^{* *}$ \\
\hline $\mathrm{F}$ (Total) & & & & & & & & & & \\
\hline
\end{tabular}

$* * p<$ at the level of $0.01, * P<.05$.

\section{RESULTS}

Results showed that Communal Orientation positive subscale positively predicted individual dimension of marital flourishing among married individuals. Likewise, communal orientation negative subscale negatively predicted relationship dimension of marital flourishing among married population (Table 3 \& 4). It was also revealed that the association between Communal Orientation \& Marital Flourishing was mediated by regulation of emotions (suppression subscale); whereas,

\section{Table 3}

Linear Regression Analysis of Positive Communal Orientation as Predictor of Marital Flourishing (Individual Dimension).

\section{Psychological Flourishing(I)}

\begin{tabular}{llllllll} 
Predictors & $\mathrm{R}$ & $\mathrm{R}^{2}$ & $B$ & $S E$ & $B$ & $T$ & $F$ \\
\hline $\mathrm{CO}(\mathrm{N})$ & .41 & .17 & .75 & .05 & .41 & 14.36 & 206.35 \\
\hline$* * * p<.001$ Note: $\mathrm{CO}(\mathrm{N})=$ Communal Positive Orientation; I= Individual Dimension of Flourishing.
\end{tabular}


Table 4

Linear Regression Analysis of Negative Communal Orientation as Predictor of Marital Flourishing (Relationship Dimension).

\begin{tabular}{llllllll}
\hline & & \multicolumn{7}{c}{ Psychological } & Flourishing(I) \\
Predictors & $\mathrm{R}$ & $\mathrm{R}^{2}$ & $B$ & $S E$ & $B$ & $T$ & $F$ \\
\hline $\mathrm{CO}(\mathrm{N})$ & .08 & .007 & .14 & .05 & -.08 & -2.73 & 7.47 \\
& & & & & & \\
\hline$* * * p<.001$ Note: $\mathrm{CO}(\mathrm{N})=$ Communal Negative orientation; $\mathrm{R}=$ Relationship Dimension of Flourishing
\end{tabular}

\section{Table 5}

Moderated-Mediation role of Emotion Expressivity and Emotion Regulation between the relationship of Communal Orientation (Predictor) and Psychological Flourishing (Outcome) among Married Individuals.

\begin{tabular}{lll}
\hline Predictors & Emotion Regulation & Marital Flourishing \\
\hline Constant & -0.1 & $71.22^{* * *}$ \\
Communal Orientation & $0.05^{* * *}$ & $0.19 * * *$ \\
Emotion Expressivity & -.04 & $-1.08^{* * *}$ \\
CO X EE & $-.02 * * *$ & \\
Emotion Regulation X EE & & $.09 *$ \\
CO X EE & & $0.04 * *$ \\
$\mathrm{R}^{2}$ & 0.04 & 0.18 \\
$\mathrm{~F}$ & $6.72 * * *$ & $41.79 * * *$ \\
$\Delta \mathrm{R}^{2}$ & 0.14 & \\
$\Delta \mathrm{F}$ & $34.7 * * *$ & \\
\hline$* p<0.05, * * p 0.01, p<0.001$ & &
\end{tabular}

$* p<0.05, * * p<0.01, p<0.001$

Note: $C O=$ Communal Orientation; EE=Emotion Expressivity. 
Figure 1: Prediction of Communal Orientation in predicting Marital Flourishing and Moderated Mediated role of Emotion Expressivity and Emotion Regulation.

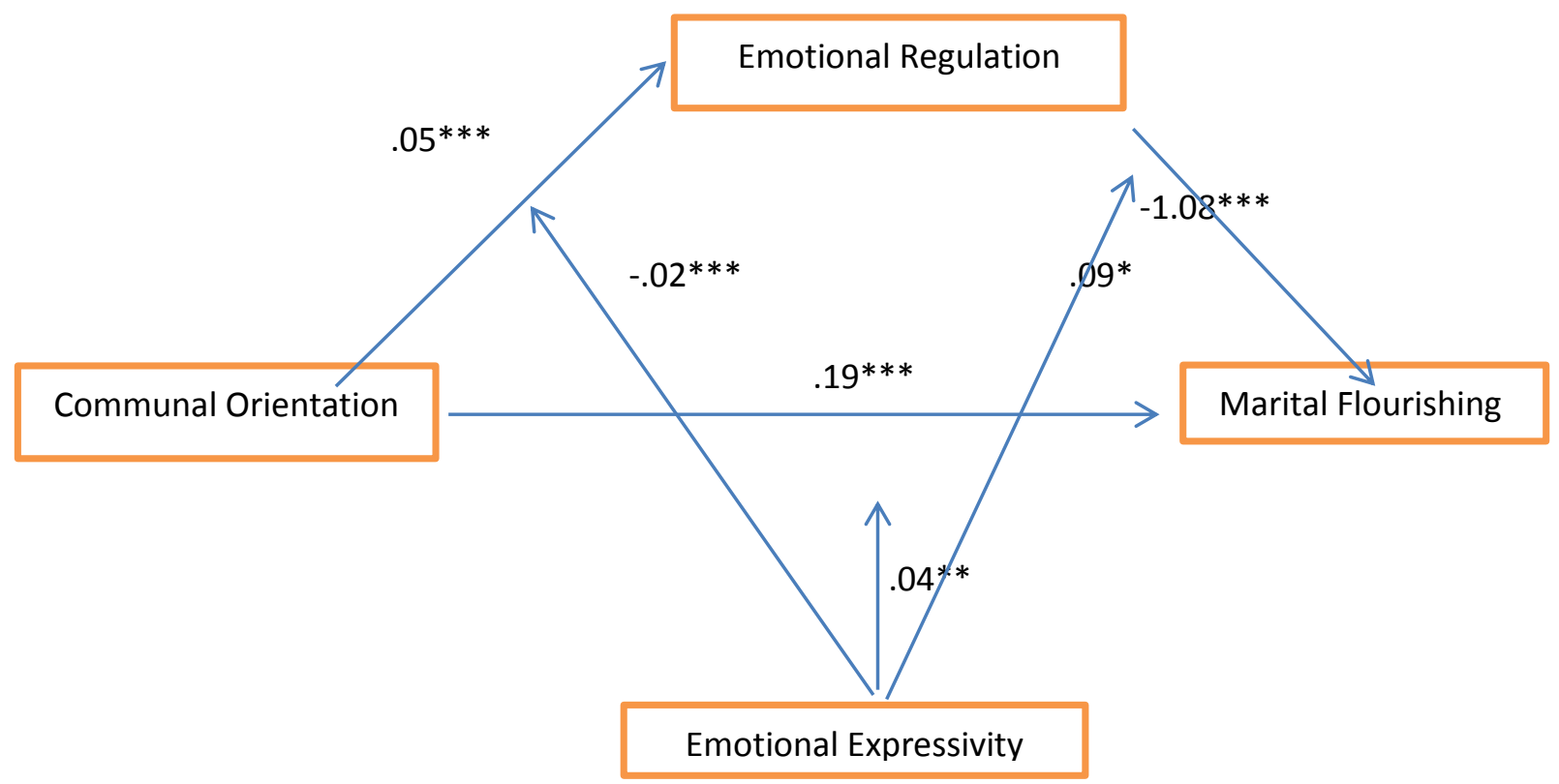

\section{DISCUSSION}

Main focus of the present research was to test the hypotheses articulated to explore the prediction of communal orientation and moderated-mediated role of emotion expressivity and emotion regulation in understanding marital flourishing of nonwestern married population.

Predictive Hypothesis: Linear regression analysis computed on the current data depicted that Communal Orientation is significant predictor of marital flourishing (Individual Flourishing $\beta=.41$ and Relationship Flourishing $\beta=-.08 ; p<.001)$.
The results are harmonized with the researches by Clark \& Finkel, (2005); Canevello \& Crocker, (2010); whose researches depicted that communal orientation increases marital flourishing through closeness, support and encouragement for the partner. Moreover, communal behaviors also reinforce the relationship flourishing factors including trust, intimacy, thankfulness and forgiveness for the spouse. Hence, communal orientation leads to a flourishing marital relationship among non-western couples. 
Moderated-Mediated Hypothesis: To explore the moderated-mediated role of emotion expressivity and emotion regulation to understand marital flourishing of husbands and wives, Macro process; Model59 was tested. ER (suppression subscale) was proved to be significantly mediating the relationship between $\mathrm{CO}$ and marital flourishing whereas, emotion expressivity (positive subscale) was found to be a significant moderator which moderates the whole meditational model. Results of the mediating effect of emotional regulation tested between relationship of Communal Orientation and Marital Flourishing showed that the relationship between Communal Orientation and Flourishing relationships was meaningfully mediated by emotional regulation. Standardized indirect effects of this mediated model was $\beta=-.02 ; 95 \% \mathrm{CI}=$ [-.04 to $.0-1]$.

Likewise, moderating effect of Emotional Expressivity was also tested. Findings showed significant direct effect of Communal Orientation and Positive Emotional Expressivity on Emotional Regulation $(\beta=.05 ; \mathrm{p}=.00)$. The interaction effect of $\mathrm{CO}$ and $\mathrm{EE}$ exert significant negative effect on ER, (suppression; interaction 1: $\beta=-.02 ; \mathrm{p}=.00)$ and flourishing, (Individual; interaction 3: $\beta=$ $.04 ; \mathrm{p}=.01)$.

Levels of Moderator: Further elaboration of the results also revealed the significance of different levels of moderator on both direct and indirect paths. For direct effects (the direct relationship between $\mathrm{CO}$ and Flourishing), low level of $\mathrm{EE}$ does not significantly moderate the direct relationship $(\beta=.08 ; p=.16)$ but moderate and high level of EE significantly buffer the relationship between $\mathrm{CO}$ and Flourishing $(\beta=.19$; $\mathrm{p}=.00)$ and $\beta=.30 ; \mathrm{p}=.00)$ respectively. For indirect paths, moderator at low level have significant effect on both indirect paths $(\beta=$ $-.07 ; 95 \% \mathrm{CI}=[-.13$ to -.03$]$ whereas moderate $(\beta=-.02 ; 95 \% \mathrm{CI}=[-.04$ to .00$]$ and high levels $(\beta=.00 ; 95 \% \mathrm{CI}=[-.01$ to .02] of moderator does not have significant effect on indirect paths. Results elucidate that low level of $\mathrm{EE}$ buffers the whole meditational model but moderate and high levels of EE do not significantly moderate this model.

Hence, it is concluded from the above discussion that communal orientation could significantly predict flourishing of nonwestern married individuals. The affiliation between communal orientation and marital flourishing is significantly moderated via 
positive expression of emotions and mediated by suppression subscale of emotion regulation. In a non-western culture, it could be interpreted that positive emotional expressivity in alliance with suppression of emotions within married context might enhance flourishing of married individuals. It could be illustrated from the current research findings that within the eastern culture, like Pakistan, inhibition of some emotions particularly within conflicting marital context and expressing positivity for the spouse seem to be beneficial for the marital relationship. Thus, it is elucidated from the current study's findings that as marital flourishing is enhanced by communal tendencies, the association is buffered by emotional mechanism.

\section{IMPLICATIONS AND}

\section{FUTURE RECOMMENDATIONS}

We believe that our work contributes to the development of an integrative theoretical understanding of communal and emotional processes and their repercussions on the married relationship, taking the non-western context as our geographical frame. Present scientific study has implications for mental professionals, health psychologists, relationship scientists and counselors who can conceptualize variables for a flourishing marital relationship.

\section{CONCLUSION}

Knowing levels of concern for each other's welfare ought to be useful within interpersonal relationships. It may be used to predict levels of flourishing, willingness to express emotion, and other important relationship phenomena. The positive psychology of close relationships builds on the work of such factors that establish healthy relations. The current study incorporates a focus on communal and emotional processes and builds a theoretical framework of appetitive processes that will tell the story of flourishing relationships. The current data revealed important empirical truth that communal dispositions exhibited by husbands and wives positively predicts marital flourishing of married individuals. While, positive emotional expressivity buffers this direct relationship through mediating role of suppression subscale of emotion regulation. The study highlights important healthy relationship variables and hence, contributes towards understanding of psychological flourishing among married population. Understanding marital flourishing also helps in stabilizing marriages and contributes towards the 
enrichment of individual's subjective wellbeing. Hence, the detailed study of all mechanisms of emotion processes provided a comprehensive understanding of flourishing of marital relationship. It would, therefore, be safe to state that emotions

\section{REFERENCES}

1. Barry R.A, Bunde M., Brock R.L., \& Lawrence, E.(2009). Validity and utility of a multidimensional model of received support in intimate relationships. Journal of Family Psychology, 23(1), 48-57. doi: $10.1037 / \mathrm{a} 0014174$.

2. Brislin, R. (1970). Back-translation for cross-cultural research. Journal of Cross Cultural Psychology, 1, 185-216.

3. Browne, M.W. \& Cudeck, R. (1993). Alternative ways of assessing model fit. In Bollen, K.A. \& Long, J.S. [Eds.] Testing structural equation models. Newbury Park, CA: Sage, $136-162$.

4. Butler, E. A. (2015). Interpersonal Affect Dynamics: It Takes Two (and Time) to Tango. Emotion Review, 7(4),33- combining with communal orientation processes have successfully captured a collective influence of diverse factors upon marital flourishing. 341.https://doi.org/10.1177/1754073915 590622

5. Butler, E. A., Egloff, B., Wilhelm, F. W., Smith, N. C., Erickson, E. A., \& Gross, J. J. (2003). The social consequences of expressive suppression. Emotion, 3, 48-67.

6. Cabello, R., Salguero, J. M., Fernández-Berrocal, P., \& Gross, J. J. (2013). A Spanish adaptation of the Emotion Regulation Questionnaire. European Journal of Psychological Assessment, 29(4), 234-

240.http://dx.doi.org/10.1027/1015$5759 / \mathrm{a} 000150$

7. Canevello, A., \& Crocker, J. (2010). Creating good relationships: Responsiveness, relationship quality, and interpersonal goals. Journal of Personality and Social Psychology, 
99(1),78-106.

http://dx.doi.org/10.1037/a0018186

8. Carrère, S., \& Gottman, J. M. (1999). Predicting divorce among newlyweds from the first three minutes of a marital conflict discussion. Family Process, 38, 293301.doi:10.1111/j.1545-

5300.1999.00293.x

9. Clark, M.S. \& Finkel, E.J.(2005). Willingness to express emotion: The impact of relationship type, communal orientation, and their interaction. Personal Relationships, 12(2),169-180.

doi.org/10.1111/j.1350-

4126.2005.00109.x

10. Clark, M.S., Ouellette, R., Powell, M.,\& Milberg,S. (1987). Recipient's mood, relationship type, and helping. Journal of Personality and Social Psychology, 53, 94-103.

11. De Leersnyder, J., Boiger, M., \& Mesquita, B. (2013). Cultural regulation of emotion: Individual, relational, and structural sources. Frontiers in Psychology, 4, Article ID 55.

12. Driver, J.L. \& Gottman, J.M., (2004). Daily marital interaction and positive affect during marital conflict among newlywed couples. Family Process, 43 (3), 301-314.

13. Emmons, R. A., \& McCullough, M. E. (2003). Counting blessings versus burdens: An experimental investigation of gratitude and subjective well-being in daily life. Journal of Personality and Social Psychology, 84(2), 377-389.

Doi.org/10.1037/002-3514.84.2.377

14. Fahd, S., \& Hanif, R. (2017). Psychological Flourishing Scale. In Progress Doctoral Dissertation. National Institute of Psychology, Quaid-e-AzamUniversity, Islamabad, Pakistan.

15. Fahd, S., \& Hanif, R. (2018). Communal orientation predicting Flourishing of Married Individuals: Mediation of Emotion Expressivity. Journal of Relationship Research, 9, E17. Doi: 10.1017/jrr.2018.16.

16. Field, A. (2009) Discovering Statistics Using SPSS. 3rd Edition, Sage Publications Ltd., London.

17. Folkman, S. \& Moskowitz, J.T. (2000). Stress, Positive Emotion and Coping. Current Directions in Psychological Science, 9 (4), 115118. 
18. Fowers, B.J. \& Owenz, M.B. (2010). A eudaimonic theory of marital quality. Journal of Family Theory and Review, 2, 334-352

19. Geist, R. L., \& Gilbert, D. G. (1996). Correlates of expressed and felt emotion during marital conflict: Satisfaction, personality, process, and outcome. Personality and Individual Differences, 21(1), 49-60. http://dx.doi.org/10.1016/01918869(96)00049-9

20. Gill, D. S., Christensen, A., \& Fincham, F. D. (1999). Predicting marital satisfaction from behavior: Do all roads really lead to Rome? Personal Relationships, 6(3), 369-387.

21. Gordon, C. L., Arnette, R. A. M., \& Smith, R. E. (2011). Have you thanked your spouse today? Felt and expressed gratitude among married couples. Personality and Individual Differences, 50, 339-343. doi:10.1016/ j. paid.2010.10.012

22. Gottman, J., M. \& Levenson, R., W. (1992). Marital processes predictive of later dissolution: Behavior, physiology, and health. Journal of Personality and Social Psychology, 63, (2), 221-233.
23. Gross, J. J., \& John, O. P. (2003). Individual differences in two emotion regulation processes: Implications for affect, relationships, and well-being. Journal of Personality and Social Psychology, 85(2), 348-362.

24. Gross, J.J., \& John, O.P. (1995). Facets of emotional expressivity: Three self-report factors and their correlates. Personality and Individual Differences, 19,555-568.

25. Haga, S. M., Kraft, P., \& Corby, E.K. (2009). Emotion regulation: Antecedents and well-being outcomes of cognitive reappraisal and expressive suppression in crosscultural samples. Journal of Happiness Studies: An Interdisciplinary Forum on Subjective Well-Being, 10(3), 271291.

26. Hair, J., Black, W., Babin, B., Anderson, R., \& Tatham, R. (2006). Multivariate data analysis (6th ed.). Uppersaddle River, N.J.: Pearson Prentice Hall.

27. John, O.P. \& Gross, J.J. (2004). Healthy and Unhealthy Emotion Regulation: Personality Processes, Individual Differences, and Life 
Span Development. Journal of Personality, 72(6), 1301-1334.

28. Khan, R. \& Kausar, R. (2014). Translation and Adaptation of Emotion Regulation Questionnaire. Unpublished Doctoral Thesis. University of Punjab, Pakistan.

29. Kogan, A., Impett, E. A., Oveis, C., Hui, B., Gordon, A. M., Keltner, D. (2010). When giving feels good: The intrinsic benefits of sacrifice in romantic relationships for the communally motivated. Psychological Science, 21, 19181924.

30. Le, B. M., Impett, E. A., Kogan, A., Webster, G. D., \& Cheng, C. (2013). The personal and interpersonal rewards of communal orientation. Journal of Social and Personal Relationships, 30(6), 695712.

31. Levenson, R. W., Haase, C. M., Bloch, L., Holley, S. R, Seider, B. H. (2013). "Emotion Regulation in Couples.” Pp. 267-283 in Handbook of emotion regulation (2nd ed.). New York, NY: Guilford.

32. Mauss, I. B., \& Gross, J. J. (2004). Emotion suppression and cardiovascular disease: Is hiding your feelings bad for your heart? In I. Nyklicek, L. R. Temoshok, \& A. Vingerhoets (Eds.), Emotional expression and health: Advances in theory, assessment, and clinical applications (pp. 62-81). New York: Brunner-Routledge.

33. Mills, J, Clark, M., S., Ford, T., E., \& Johnson, M. (2004). Measurement of communal strength. Personal Relationships, 11, 213-230. 34. Mills, J., \& Clark, M. S. (2001). Viewing close romantic relationships as communal relationships: Implications for maintenance and enhancement. In J. Harvey \& A. Wenzel (Eds.), Close romantic Communal strength relationships: Maintenance and enhancement. (pp. 13-25). Hillsdale, NJ: Erlbaum.

35. Mirgain, S. A., \& Cordova, J. V. (2007). Emotion skills and marital health: The association between observed and self-reported emotion skills, intimacy, and marital satisfaction. Journal of Social and Clinical Psychology, 26(9), 9831009.

doi.org/10.1521/jscp.2007.26.9.983

36. Oprisan, E., \& Cristea, D. (2012). A few variables of influence in the 
concept of marital satisfaction. Procedia-Social and Behavioral Sciences, $\quad 33, \quad 468-472$. http://dx.doi.org/10.1016/j.sbspro.2 012.01 .165

37. Orathinkal, J., \& Vansteenwegen, A. (2006). The Effect of Forgiveness on Marital Satisfaction in Relation to Marital Stability. Contemporary Family Therapy: An International Journal, 28(2), 251-260. http://dx.doi.org/10.1007/s10591006-9006-y

38. Stanley, S.M., Whitton S.W., Sadberry S.L., Clements, M. L, \& Markman, H. J. (2006). Sacrifice as a predictor of marital outcomes. Family Process, 45(3), 289-303.

39. Wang, Y., Wang, D., Feeney, B. C., \& Li, F. (2017). What will I tell you about my marriage? The relationship between attachment and autobiographical memory of married life. Journal of Social and Personal Relationships, 34(7),96-

98. https://doi.org/10.1177/02654075 16664417
40. Watkins, P., Woodward, K., Stone, T., \& Kolts, R. (2003). Gratitude and happiness: Development of a measure of gratitude and relationships with subjective wellbeing. Social Behavior and Personality: An international journal, 31,431452.https://doi.org/10 $.2224 / \mathrm{sbp} .2003 .31 .5 .431$

41. Yedirira, S., Hamarta,E. (2015). Emotional Expression and Spousal Support as Predictors of Marital Satisfaction: The Case of Turkey. Educational Sciences: Theory \& Practice, 15(6), 1549-1558

42. Yoo, H., Bartle-Haring, S., Day, R. D., \& Gangamma, R. (2014). Couple communication, emotional and sexual intimacy, and relationship satisfaction. Journal of Sex and MaritalTherapy, 40(4),275-

293. https://doi.org/10.1080/0092623 X.2012.751072

43. Ziv, A., \& Gadish, O. (1989). Humor and marital satisfaction. The Journal of Social Psychology, 129(6),759768. 